\title{
Interview on Kinship and Household
}

\section{Bogl, Leonie-Helen}

Springer

2019

Bogl , L-H , Kaprio , J , Brunings-Kuppe , C , Lissner , L \& Ahrens , W 2019 , Interview on Kinship and Household . in K Bammann , L Lissner , I Pigeot \& W Ahrens (eds), Instruments for Health Surveys in Children and Adolescents. Springer Series on Epidemiology and Public Health , Springer, Switzerland , pp. 291-301 . https://doi.org/10.1007/978-3-319-98857-3_14

http://hdl.handle.net/10138/319535

https://doi.org/10.1007/978-3-319-98857-3_14

acceptedVersion

Downloaded from Helda, University of Helsinki institutional repository.

This is an electronic reprint of the original article.

This reprint may differ from the original in pagination and typographic detail.

Please cite the original version. 


\title{
14 Interview on Kinship and Household
}

\author{
Leonie-Helen Bogl, Jaakko Kaprio, Claudia Brünings-Kuppe, Lauren \\ Lissner and Wolfgang Ahrens \\ on behalf of the I.Family consortium
}

\author{
Leonie-Helen Bogl ( $₫)$, bogl@1eibniz-bips.de \\ Leibniz Institute for Prevention Research and Epidemiology - BIPS, Bremen, Germany \\ and \\ Institute for Molecular Medicine (FIMM), University of Helsinki, Helsinki, Finland \\ Jaakko Kaprio \\ Institute for Molecular Medicine (FIMM), University of Helsinki, Helsinki, Finland \\ Claudia Brünings-Kuppe \\ Leibniz Institute for Prevention Research and Epidemiology - BIPS, Bremen, Germany \\ Lauren Lissner \\ Section for Epidemiology and Social Medicine (EPSO), Department of Public Health and \\ Community Medicine, Sahlgrenska Academy, University of Gothenburg, Gothenburg, \\ Sweden \\ Wolfgang Ahrens \\ Leibniz Institute for Prevention Research and Epidemiology - BIPS, Bremen, Germany \\ and \\ University of Bremen, Faculty of Mathematics and Computer Science, Bremen, Germany
}

\begin{abstract}
As parents transmit their genes to their children and also provide the rearing environment, the family profoundly shapes the development and behaviour of a growing child. In the European I.Family study, we aimed to quantify the degree of familial resemblance in anthropometric measures and indices of obesity, cardio-metabolic risk factors, diet quality, taste preference and indicators of sleep using a pedigree file. Familial resemblance can arise from shared genes and shared environments and in the case of spousal correlations, assortative mating or social homogamy. This chapter explains the instrument used in I.Family to assess household composition and size and to identify biological and non-biological relationships in the household. We describe the design of the kinship interview and the challenges encountered in its implementation.
\end{abstract}




\subsection{The Role of the Family in Children's Development}

The family is important in the development of children and adolescents. Parents, siblings and other relatives provide the closest personal, social and psychological support to foster the physical and mental development of a young human. Thus, familial influences are seen not only on normal traits, such as growth, eating behaviours and physical activity, but also when these are disturbed as in obesity or sedentary behaviour. Parents influence the development of their children directly through multiple mechanisms such as genetic makeup, parental norms and modelling of parental behaviours and indirectly through choosing neighbourhoods. The role of parents is a major one during infancy and early childhood. Their influence decreases as the child grows up and becomes exposed to other environments like day care, school and peer groups. In adolescence peer influences play a much greater role, as the child becomes more independent of his or her family.

Family members share social, psychological and economic environments but only biological relatives are also genetically related. Parents and siblings are considered first-degree relatives, sharing on average $50 \%$ of segregating genes (Thomas 2004), while grandparents, aunts and uncles are defined as genetically more distant second-degree relatives. In a pedigree (family tree), various biological and social relationships can be identified. Family members generally resemble each other more on most characteristics including obesity and food intake compared to two unrelated individuals from the same community (Bogl et al. 2017; Chaput et al. 2014). Familial resemblance can be attributed both to material and psychosocial factors in the family and to genetic relatedness of family members. The relative roles of genetic and non-genetic influences for siblings are readily documented using twin studies (Polderman et al. 2015). In order to study the causes and consequences of familial resemblance, information of the family and its constituents needs to be collected and documented. For this purpose, an instrument was created in I.Family based on experiences of the research group and prior literature.

\subsection{The Interview}

The design of the interview was a challenging task. We had to assess not only the social and the biological relationships within a family but also the composition of the household and - in case that parents were separated - the household(s) to which the child belonged. In addition, the interview had to allow for more than one participating child and for all possible combinations of biological and nonbiological relationships between family members living in different households as is often the case in so-called "blended families". All these requirements resulted in 
a complex instrument not suitable for self-completion (for access see Section 14.7).

The interview was mainly conducted with one parent or legal guardian using a Computer Assisted Telephone Interviewing (CATI) or Computer Assisted Personal Interviewing (CAPI). In case of technical problems, a paper version was used as a back-up for both, face-to-face or telephone interview. A flowchart depicting the branching structure of the instrument to assess family relationships and household composition is shown in Figure 14.1.

$<<$ Insert Figure 14.1 about here $>>$

The kinship interview was conducted by contacting the households of the children who already participated in the IDEFICS study. The child who already participated in the IDEFICS study was set as the so-called index child. If a family had multiple children who already participated in the IDEFICS study, the older/oldest child was chosen as the main index child. At the beginning of the interview, a set of questions was asked to inquire information about the relationship of the interviewee to the chosen index child and to ensure that the interview was taking place at the main household, where the child lived $50 \%$ or more of the time. If a child lived $50 \%$ or more in another household, the phone number of the parent living with that index child in the other household was asked so that this second household could be contacted later as well. If there was another index child living 50\% or more in the current (first) household, the interview was restarted for that other index child. If there was no other index child living $50 \%$ or more in the household, the interview was continued with the current index child despite the fact that this child lived $50 \%$ or less in that household. This was done because it was not certain that the second household where the child lived $50 \%$ or more of the time could always be reached. The second household was also contacted, if possible, after completing the interview with the first household.

After the information on the household was inquired, the interviewer asked about the number of children and adults above the age of 18 in the household. The following information was inquired for adults: name, sex, age and the relationship to the chosen index child. This was repeated for as many adults as there were in the household. The interview inquired the following information for children: IDEFICS ID number (for all children who already had participated in the IDEFICS study), the child's birth date, the child's sex, the name of his/her school, and the relationship of that child to the chosen index child. The questions were repeated for all children in the household. A final question inquired information on the presence and number of other biological sibling(s) or half-siblings living outside this household. The interviewer assigned one of the following family relationship codes for each individual in the household presented in Table 14.1. Each person was assigned a kinship ID number. 
Table 14.1 Assignment of codes to family members with i1 denoting the chosen index child in the household

\begin{tabular}{|c|c|}
\hline Code & Person in household \\
\hline$i 1$ & Chosen index child in household \\
\hline 01 & Biological mother of i1 \\
\hline $\mathbf{0 2}$ & Biological father of il \\
\hline 03 & $\begin{array}{l}\text { Biologically unrelated female adult who can be step-mother/adoptive mother/foster } \\
\text { mother/new partner of biological mother or father of i1 }\end{array}$ \\
\hline 04 & $\begin{array}{l}\text { Biologically unrelated male adult who can be step-father/adoptive father/foster } \\
\text { father/new partner of biological mother or father of i1 }\end{array}$ \\
\hline 05 & Other adult (any relationship, biologically related or unrelated) \\
\hline 11 & $\begin{array}{l}\text { Biological sibling of i1 (this code has also to be used for siblings who already had } \\
\text { participated in the IDEFICS study, i.e. for non-chosen index children) }\end{array}$ \\
\hline 12 & Half-sibling of i1 (same biological mother or same biological father) \\
\hline 13 & $\begin{array}{l}\text { Non-biological sibling of i1 (e.g. adopted sibling, foster sibling, child of step- } \\
\text { father/step-mother unrelated to i1) }\end{array}$ \\
\hline
\end{tabular}

Table 14.2 gives an overview of the household types and the average number of household members in I.Family by the eight countries as assessed by the kinship interview. The most common household type was a child or siblings living with both biological parents (74\%). Households in which a child or full siblings lived with only one biological parent comprised $11 \%$ of all households, of which $90 \%$ were single-mother households. Finally, $14 \%$ of the households were so-called "blended families", which included various combinations of step-parents, singleparents, half-siblings or other household members. Overall, half- or step-siblings were present in $6 \%$ of the households, of which most included half-siblings $(5 \%$ half-siblings, $1 \%$ step-siblings).

The interview collected information on all household members; thus, it also included relationship information of non-participants. I.Family aimed to recruit at least one parent and in the case of siblings, at least one sibling of the index children who already had participated in the IDEFICS study. On average, 2.9 out of 4.1 family members living in a household were recruited in I.Family. Although $14.3 \%$ of the index children lived in households where non-biologically related relatives such as step-parents, step- or half-siblings or other adults (e.g. aunt/uncle or grandparents) were present, the index children were more likely to participate in I.Family with their first-degree relatives (biological parents and their biological siblings). Thus, out of the participating family members for whom we have data, $97 \%$ were first-degree relatives. 
Table 14.2 Household types in I.Family by country

\begin{tabular}{|c|c|c|c|c|c|c|c|c|c|c|}
\hline $\begin{array}{l}\text { Household } \\
\text { types }\end{array}$ & & Italy & Estonia & Cyprus & Belgium & Sweden & Germany & Hungary & Spain & All \\
\hline \multirow[b]{2}{*}{$\begin{array}{l}\text { Households } \\
\text { where } \\
\text { child(ren) } \\
\text { lived with } \\
\text { both } \\
\text { biological } \\
\text { parents }^{1}\end{array}$} & $\mathrm{n}$ & 844 & 313 & 1027 & 65 & 427 & 506 & 470 & 254 & 3906 \\
\hline & $\%$ & 85.2 & 60.3 & 82.1 & 72.2 & 77.4 & 66.9 & 61.5 & 75.8 & 74.3 \\
\hline \multirow[b]{2}{*}{$\begin{array}{l}\text { Households } \\
\text { where } \\
\text { child(ren) } \\
\text { lived with } \\
\text { one } \\
\text { biological } \\
\text { parent }^{2}\end{array}$} & $\mathrm{n}$ & 51 & 72 & 108 & 11 & 79 & 116 & 116 & 45 & 598 \\
\hline & $\%$ & 5.1 & 13.9 & 8.6 & 12.2 & 14.3 & 15.4 & 15.2 & 13.4 & 11.4 \\
\hline \multirow{2}{*}{$\begin{array}{l}\text { All other } \\
\text { households }\end{array}$} & $\mathrm{n}$ & 96 & 134 & 116 & 14 & 46 & 134 & 178 & 36 & 754 \\
\hline & $\%$ & 9.7 & 25.8 & 9.3 & 15.6 & 8.3 & 17.7 & 23.3 & 10.8 & 14.3 \\
\hline $\begin{array}{l}\text { Number of } \\
\text { household } \\
\text { members } \\
\text { (mean) }\end{array}$ & $\mathrm{n}$ & 4.2 & 3.9 & 4.4 & 4.3 & 4.1 & 4.0 & 3.9 & 4.0 & 4.1 \\
\hline
\end{tabular}

Note: ${ }^{1} \mathrm{~A}$ two-parent household, where a child lived with both biological parents, either as a single child or with full siblings; ${ }^{2} \mathrm{~A}$ single parent household, where a child lived with one biological parent, either as a single child or with full siblings; ${ }^{3} \mathrm{~A}$ so-called "blended family" where a child lived with nonbiological parents such as step-parents and/or step- or half-siblings and/or other adults in the household (various combinations possible, and first-degree relatives may also be present)

Because at the time of the interview, it was not clear yet which household members would participate in the I.Family study, the kinship file included a kinship ID (identification) number for all persons living in the household but not the individual ID number which has been used for all other data in the study. Thus, we had to use three different approaches to merge the individual ID numbers to the kinship data:

1. For the IDEFICS children the linkage was possible via the IDEFICS ID number.

2. For newly participating children, the family ID number, the sex and the birthdate were used.

3. The age of adult family members was partly reported by other family members. Because this information was considered as less valid than self-reported age, data were merged via the family ID number, the sex and the age allowing for an error range of \pm 2.5 years. 


\subsection{Creation of a Pedigree File}

A pedigree file that describes the biological and non-biological relationships between individuals in the dataset is typically required by most statistical genetic analysis programs for family data. Siblings can be identified by having common parents. Full siblings will have the same mother and father ID numbers, while half-siblings will only share either the mother or father ID. Although pedigrees can become complex, most commonly only the five following variables are needed to create the pedigree file: a family identifier (family ID number), an identifier for the individual (individual ID number), two parent identifiers (father ID and mother ID numbers) and an indicator of each individual's sex.

A blank parental ID number is commonly used for individuals whose parents are not in the pedigree and this indicates that the individual is a founder. Founders are assumed to be biologically unrelated. Some software requires that either both parents are unknown or both parents are known where knowledge refers to identity and not knowledge about phenotypes or genotypes. In order to correctly identify biological and non-biological relationships in the sample, this may require the creation of fictitious parental ID numbers for individuals who did not participate in the study. As an example of how family relationships may be labelled in a pedigree file, Table 14.3 shows a small pedigree consisting of two siblings and their parents, where a fictitious father ID number has been created to indicate that the siblings are full siblings.

Table 14.3 Extract of a pedigree file used in the analysis of biological and non-biological relationships in a family

\begin{tabular}{|c|c|c|c|c|c|}
\hline $\begin{array}{l}\text { Family ID } \\
\text { number }\end{array}$ & $\begin{array}{l}\text { Individual ID } \\
\text { number }\end{array}$ & $\begin{array}{l}\text { Father ID } \\
\text { number }\end{array}$ & $\begin{array}{l}\text { Mother ID } \\
\text { number }\end{array}$ & Sex & Phenotype data \\
\hline FAM001 & ID004F & & & Male & not available \\
\hline FAM001 & ID005 & & & Female & available \\
\hline FAM001 & ID006 & ID004F & ID005 & Male & available \\
\hline FAM001 & ID007 & ID004F & ID005 & Female & available \\
\hline
\end{tabular}

Note: The fictitious ID number (ID004F) was created for the non-participating father.

\subsection{Analysis of Family Data}

Family studies are useful to assess whether a trait of interest runs in families. Family resemblance can arise from shared genes and shared environments and in the case of spousal correlations from assortative mating or social homogamy (Thomas 2004). Often the first question to address is whether a specific trait is 
influenced by genetic differences at all. If a trait is only weakly genetically determined, this may have important implications for gene-finding efforts, and for efforts to influence the trait value through interventions. For quantitative traits, familial correlations can be estimated for pairs of relatives using a covariancebased measure. The degree of resemblance between two family members of the same classes of individuals (e.g. sibling pairs) can be estimated by the intraclass correlation coefficient (ICC) and the degree of resemblance between two family members from different classes of individuals (e.g. parent-offspring) by the interclass correlation coefficient. Higher correlation coefficients imply a stronger familial resemblance.

In I.Family we calculated intra- and interclass correlations by using the FCOR program of the Statistical Analysis for Genetic Epidemiology software package (SAGE, version 6.3) (Elston and Gray-McGuire 2004). FCOR calculates multivariate familial correlations with their asymptotic standard errors without assuming multivariate normality of the traits across family members (Keen and Elston 2003). It calculates familial correlations for all relative pair types available in the pedigree file (see Section 14.3).

If a trait aggregates in families, the next step is to quantify the contributions of genetic and environmental factors to phenotypic variation. Family and twin studies are widely used to quantify the proportion of phenotypic variance attributable to genetic effects. Twin studies as a unique case of family studies are analysed with complex modelling and variance decomposition methods that are described in detail elsewhere (Neale and Maes 2004). Family studies can include nuclear families (parents and their offspring) or extended pedigrees (grandparents, parents, offspring, cousins, etc.). Heritability from twin or extended family studies refers to the proportion of the total variance in a particular trait that is explained by genetic factors only. It is important to remember that phenotypic data on nuclear families alone do not enable the estimation of the relative contribution of genetic and shared environmental components on phenotypic variation. Family studies that have mainly data only on first-degree relatives can be used to assess only overall "familiality", i.e., the proportion of phenotypic variance attributable to the combined effects of all familial influences (Kendler and Neale 2009). Other common terms for familiality previously used as synonyms in the literature are maximal heritability and transmissibility.

In I.Family we estimated "familiality" using a maximum-likelihood variance component method implemented in SOLAR (Sequential Oligogenic Linkage Analysis Routines) (Southwest Foundation for Biomedical Research). The variance decomposition method is based on the fact that biologically related relatives share a certain amount of genes identical by descent (IBD) and relatives living in the same household share environmental factors. Thus, the correlations between any pair of relatives depend on their degree of genetic and shared environmental relationships. For example, biological siblings and parents and their offspring share $50 \%$ of their segregating genes IBD, while spouse pairs are assumed not to share any genes. All types of relative pairs living in the same 
household are matched for shared environmental factors, and differences among biologically related family members are attributable to their unique environmental factors. Greater familial resemblance for biological than non-biological siblings or for monozygotic $(100 \%$ of genetic variation IBD) than dizygotic twins $(50 \%$ of genetic variation IBD) would thus suggest a genetic contribution to the phenotype.

\subsection{Parenting Style in I.Family}

In addition to kinship and household structure, the family questionnaire (FQ) (see Chapter 9 "Core Questionnaires" of this book) assessed several aspects of parenting style to study influences on diet and other health-related factors. Questions about the family, not specific to one child, were answered by the father or mother. Topics here included description of the family atmosphere, joint activities, and rules about media use (Latendresse et al. 2009; Rideout et al. 2010). In the parental questionnaire (PQ) (see Chapter 9 "Core Questionnaires" of this book), mothers and fathers gave their views on parental versus school responsibilities about healthy lifestyles, parental engagement in their children's activities, and authoritarian versus permissive parenting styles were described (questions taken from the respective IDEFICS questionnaires).

In the teen questionnaire (TQ) children 12 years and older reported rules about being out at night (Pearson et al. 2010), and in addition answered "mirror image" questions describing their own perceptions of the family atmosphere, which correspond to those answered by their parents (Latendresse et al. 2009).

\subsection{Challenges}

Modern family structures can be quite complex as well as dynamic over time. Thus, the design and implementation of the kinship interview was a challenging task. Our experience showed that some aspects of the interview can be further improved, and that the training of the interviewer is very important. We have noticed that some of the interviewers mistakenly assigned the relationship code "i1" for more than one child in a household (despite the instruction to assign the code "i1" only for the oldest index child in case there was more than one index child in the household). This led to the fact that for sibling pairs for which both children were assigned the relationship code "il", it is not possible to tell whether they are full siblings, half-sibling or non-biological-siblings. Furthermore, the relationship code " 05 " which stands for "Other adult (any relationship, biologically related or unrelated)" was intended for other adults that did not fit into categories "01-04". However, the formulation obviously has led to some confusion among the interviewers and the code " 05 " was also assigned to some of 
the step-parents (for which the relationship codes 03 or 04 were intended). Therefore, if the instrument is used in the future, we recommend reformulating the category " 05 " to "Other adult (any other relationship, for example aunt/uncle or grandparents)". All of the three categories (03-05) comprise adults that are nonfirst degree relatives. In I.Family, such family members were excluded from the analysis of familial resemblance since this analysis was restricted to biological parents and full siblings. In other settings, characterisation of second-degree relatives may also be desirable and so the coding would needed to be appropriately modified.

In I.Family, the examination of family members was restricted to those living in the same household as the index child. This limits the possibility of the analyses to distinguish between genetic and non-genetic familial effects. Although a substantial proportion of children did live in so-called "blended families", their proportion in the study sample was much smaller because the recruitment of such family members was not a central aim of I.Family. In fact, in case the response proportion was so good that the survey centres needed to decide which children should be included in the study, biological siblings were prioritized over nonbiologically related siblings. Studies of first-degree relatives can tell us whether a trait is familial or not, but they cannot disentangle genetic from familial environmental sources of resemblance. It is also important to remember that familial correlations and the relative importance of familial vs. non-familial factors can vary among populations depending on genetic and environmental circumstances. With the advent of molecular genetic techniques and large-scale genotyping, genetic relationships can be confirmed and polygenic risk scores can be used to provide additional information about the actual strength of the relationship for any relative pair with respect to the study trait.

\subsection{Provision of Instruments and Standard Operating Procedures to Third Parties}

All instruments described in this chapter including the General Survey Manual that provides among other all standard operating procedures can be accessed on the following website: www.leibniz-bips.de/ifhs after registration.

Each third partner using the instruments provided in this chapter is kindly requested to cite this chapter as follows:

Bogl L-H, Kaprio J, Brünings-Kuppe C, Lissner L, Ahrens W, on behalf of the I.Family consortium. Interview on kinship and household. In: Bammann $\mathrm{K}$, Lissner L, Pigeot I, Ahrens W, editors. Instruments for health surveys in children and adolescents. Heidelberg: Springer Publisher; 2018. p. xx-yy. 


\section{Acknowledgments}

The development of instruments, the baseline data collection and the first follow-up work as part of the IDEFICS study (www.idefics.eu) were financially supported by the European Commission within the Sixth RTD Framework Programme Contract No. 016181 (FOOD). The most recent follow-up including the development of new instruments and the adaptation of previously used instruments was conducted in the framework of the I.Family study (www.ifamilystudy.eu) which was funded by the European Commission within the Seventh RTD Framework Programme Contract No. 266044 (KBBE 2010-14).

We thank all families for participating in the extensive examinations of the IDEFICS and I.Family studies. We are also grateful for the support from school boards, headmasters and communities. We greatly appreciate the input provided by Marcus Zaja, Leibniz Institute for Prevention Research and Epidemiology - BIPS, Bremen, Germany.

\section{References}

Bogl LH, Silventoinen K, Hebestreit A, Intemann T, Williams G, Michels N, et al. Familial resemblance in dietary intakes of children, adolescents, and parents: Does dietary quality play a role? Nutrients. 2017;9(8).

Chaput JP, Perusse L, Despres JP, Tremblay A, Bouchard C. Findings from the Quebec Family Study on the etiology of obesity: genetics and environmental highlights. Curr Obes Rep. 2014;3:54-66.

Elston RC, Gray-McGuire C. A review of the 'Statistical Analysis for Genetic Epidemiology' (S.A.G.E.) software package. Hum Genomics. 2004;1(6):456-9.

Keen KJ, Elston RC. Robust asymptotic sampling theory for correlations in pedigrees. Stat Med. 2003;22(20):3229-47.

Kendler KS, Neale MC. "Familiality" or heritability. Arch Gen Psychiatry. 2009;66(4):4523.

Latendresse SJ, Rose RJ, Viken RJ, Pulkkinen L, Kaprio J, Dick DM. Parental socialization and adolescents' alcohol use behaviors: predictive disparities in parents' versus adolescents' perceptions of the parenting environment. J Clin Child Adolesc Psychol. 2009;38(2):232-44.

Neale MC, Maes HHM. Methodology for genetic studies of twins and families. Dordrecht: Kluwer Academic Publisher; 2004.

Pearson N, Atkin AJ, Biddle SJ, Gorely T, Edwardson C. Parenting styles, family structure and adolescent dietary behaviour. Public Health Nutr. 2010;13(8):1245-53.

Polderman TJ, Benyamin B, de Leeuw CA, Sullivan PF, van Bochoven A, Visscher PM, et al. Meta-analysis of the heritability of human traits based on fifty years of twin studies. Nat Genet. 2015;47(7):702-9.

Rideout VJ, Foehr UG, Roberts DF. Generation M2: media in the lives of 8-18 year-olds. In: Kaiser Family Foundation; 2010. http://www.kff.org/entmedia/upload/8010.pdf. Accessed 29 Mar 2018.

Thomas DC. Statistical methods in genetic epidemiology. New York: Oxford University Press; 2004. 


\section{FIGURE LEGENDS}

Fig. 14.1 Flowchart illustrating the branching structure of the instrument to assess family relationships and household composition 